\title{
Optimum Design of Reinforced Concrete Cantilever Retaining Walls according Eurocode 2 (EC2)
}

\author{
By Fouad A. Mohammad* \\ Hemin G. Ahmed
}

This study investigates optimum design in terms of minimum cost of reinforced concrete cantilever retaining walls. For the optimization process, the evolutionary method which is a combination of genetic algorithm and local search techniques was implemented. Evolutionary method was adopted in this study because it can effectively solve highly nonlinear problems and problems that feature discontinuous functions as demonstrated by several works available in the literature. The popularity of the evolutionary method may also be attributed to its availability as one of the solving methods in Solver add-in tool of Microsoft Excel. This implies that it is freely available and no need to pay for extra license to run any optimization problem. The design variables of the problem are thickness of stem wall, thickness of base slab, width of the heel, width of the toe, area of steel reinforcement for the stem wall and base slab. The objective function was to minimise the total cost of the wall, which includes costs of concrete, steel, forming, and excavation. The constrained functions were set to satisfy provisions and requirements of Eurocode 2 (EC2). Material strength and soil characteristics are treated as design parameters where they are kept constants during solution of the problem. Various material cost ratios were considered. Consequently, optimum design charts were developed for a wide range of wall height, coefficient of friction and surcharge load. Following a comprehensive investigation of the minimum cost problems carried out for different cases, one can conclude that the total cost of the retaining wall is directly proportional to the wall height and surcharge load values, whereas, the cost is almost independent of coefficient of friction.

Keywords: Eurocode 2 (EC2), Evolutionary method, Excel Solver, Reinforced concrete, Retaining wall, Optimization.

\section{Introduction}

Reinforced concrete cantilever retaining walls are one of the most commonly used structures in the field of civil engineering with numerous applications. They are most frequently used for roads, bridge abutments and other built facilities. Generally, the conventional design of reinforced cantilever retaining wall is very safe, but in terms of cost it can be considered uneconomic, in addition to requiring significant time and its total reliance on the designer's experience.

The main parameters for evaluating a successful design are cost economy and satisfaction of code requirements, yet, without compromising the functional purposes the structure meant to serve for. Following a systematic optimum design will definitely ensure the combination of these parameters (cost, specifications and

${ }^{*}$ Senior Lecturer, Nottingham Trent University, UK.

${ }^{\dagger}$ MSc Student, Nottingham Trent University, UK. 
function).Optimization can be defined as a procedure of maximizing or minimizing a desired objective (Belegundu and Chandrupatla, 2011). There are various methods established to apply and achieve an optimum solution for any specific problem. Among these methods areSequential Quadratic Programming (SQP), Generalised Reduced Gradient (GRG) and "Genetic Algorithms (GA), (Arora, 2012). Furthermore, Microsoft Excel Solver and Matlab are considered effective tools to apply this process without being involved with the mathematical complication and the computer program setting of any selected optimization technique.

The greater part of the optimization of structures is joined with minimization of the mass of the construction. Meanwhile for concrete composition the function of the objective to be minimized has to be the cost because it includes various materials. Generally speaking, there are three main different parameters which may be taken into account in optimization problems of reinforced concrete structures. They are concrete, steel, and the formwork costs (Adeli and Sarma, 2006).

The design optimization of various types of reinforced concrete retaining walls have been addressed by many researchers in the literature. The following is a review to some of these works.

Medhekar (1990) investigated the optimum design of free cantilever retaining walls. Two different types of foundation were assumed which are rigid and flexible. The objective function was to minimise the total cost of the structure. The method of the interior penalty function was used to solve the problem of nonlinear optimum design. The requirement for the stability and structural strength were represented as constraints. The results showed that the minimum cost of a wall with a height varying from 3 to $6 \mathrm{~m}$ for the rigid foundation was slightly higher than for a corresponding wall and flexible foundation. This means that the flexibility of the foundation has no significant effect on the cost of retaining walls.

Basudhar et al. (2006) investigated the optimal cost design of cantilever retaining walls of a particular height that satisfies the constraints of some structural and geotechnical designs. Seven design variables were taken into consideration, which are base width, toe width, thickness of stem, thickness of base, minimum width of embedment, reinforced rod diameter and top width of stem. The method of sequential unconstrained minimization along with Powell's algorithm for multidimensional searches and the method of quadratic interpolation for onedimensional searches were adopted. It was noticed that by increasing the top of the stem from 10 to $30 \mathrm{~cm}$, the cost would be increased by $9 \%$ to $15 \%$.

Poursha et al. (2011) studied the optimum cost of the reinforced cantilever retaining wall of satisfying a number of geotechnical and structural constraints using harmony search algorithms. The design variables were the stem thickness at the top, the stem thickness at the bottom, toe width, heel width, stem height, base slab thickness and key depth. The object function was to minimise total cost of the design and construction according to ACI 318-05. The procedure of optimum design was divided into two stages. Firstly, checking for stability, which included overturning, sliding and bearing capacity failures. Secondly, checking each part of the cantilever wall for the strength and required steel. The same process of 
optimization was repeated for two types of backfill using MATLAB, and the mathematical results showed that the solution of improved harmony search algorithm was better, when compared to a traditional harmony search method.

Pei and Xia (2012) followed heuristic optimization algorithms to design a reinforced cantilever retaining wall. The main goal of this investigation was to design the wall automatically with minimum cost. The objective function was the minimum cost of the retaining wall which comprises the cost of concrete and reinforcements per meter length of the wall. The costs of labour, framework, steel fixing and losses of material were neglected for sake of simplicity. Three types of heuristic algorithms were approached for solving the constrained model of optimization including Genetic Algorithm (GA), Particle Swarm Optimization (PSO) and Simulated Annealing (SA). The main outcomewas that the application of heuristic optimization algorithms is very effective in the design of a reinforced cantilever retaining wall with minimum cost. It was recommended that the particle swarm optimization was the most effective and efficient among the three methods used. With regard to cost, it was found that the design gained by the method of heuristic optimization algorithms was half as expensive as the traditional design method.

Sheikholeslami et al. (2014) developed a novel optimization technique known as hybrid firefly algorithm with harmony search technique (IFA-HS) in order to obtain the optimal cost of reinforced concrete retaining walls satisfying the stability criteria and design provisions of ACI 318-05. Some design examples were tested using this new method from which the results confirmed the validity of the proposed algorithm. The method demonstrated its efficiency and capability of finding least-cost design of retaining walls that satisfy safety, stability and material constraints.

\section{Design Formulation}

The design procedure of a retaining wall is mainly divided into two main steps which are stability and strength checking and requirements as explained in the following sections.

\section{Stability Checking}

For a retaining wall having geometry and dimensions shown in Figure 1 and list of notations shown at the end of the paper, the active earth pressure coefficient $\left(\mathrm{K}_{\mathrm{a}}\right)$ is defined as:

$$
K_{a}=(1-\sin \varphi) /(1+\sin \varphi)
$$

The total horizontal force that attempts to slide the wall $\left(\mathrm{P}_{1}\right)$ is:

$$
P_{1}=K_{a} \gamma H_{1}^{2} / 2+K_{a} q H_{1}
$$


Ignoring passive earth pressure due to its very small value, the resisting force to sliding is simply the total vertical load (W) multiplied by the coefficient of friction $(\mu)$ between the base slab and the supporting soil, i.e.

$F_{\text {res }}=\mu W$

By neglecting the difference in unit weight between soil and concrete and the weight of the toe slab of width b1, the total vertical load which is sum of the weight of eight of the wall stem, base slab, earth backfill on the base and surcharge load at the top, can be conservatively approximated as, (Bhatt et al., 2013):

$W=\gamma b_{2} H_{1}+q b_{2}$

Hence,

$F_{\text {res }}=\mu\left(\gamma b_{2} H_{1}+q b_{2}\right)$

The minimum recommended value of factor of safety against sliding is 1.2 , (Bhatt et al., 2013). Therefore,

$F S_{\text {slid }}=\frac{F_{\text {res }}}{P_{1}} \geq 1.2$

If the centre of gravity of the sum of the vertical loads is located at distance (x) from the toe of the wall, the stabilizing or restoring moment $\left(\mathrm{M}_{\mathrm{st}}\right)$ with partial safety factor $\left(\gamma_{\mathrm{G}, \text { fav }}\right)=1$ with respect to overturning about the toe will be:

$M_{s t}=W x$

The overturning moment $\left(\mathrm{M}_{\mathrm{ot}}\right)$ due to the active earth pressure with partial safety factor $\left(\gamma_{Q}\right)=1.5$ can be calculated as:

$M_{o t}=\gamma_{Q}\left(K_{a} \gamma H_{1}^{3} / 6+K_{a} q H_{1}^{2} / 2\right)$

The factor of safety against overturning should always be greater than one and can be expressed mathematic ally as:

$F S_{\text {ovtr }}=\frac{M_{\text {st }}}{M_{\text {ot }}} \geq 1$ 
Figure 1. Retaining Wall Dimensions and Forces Acting on It

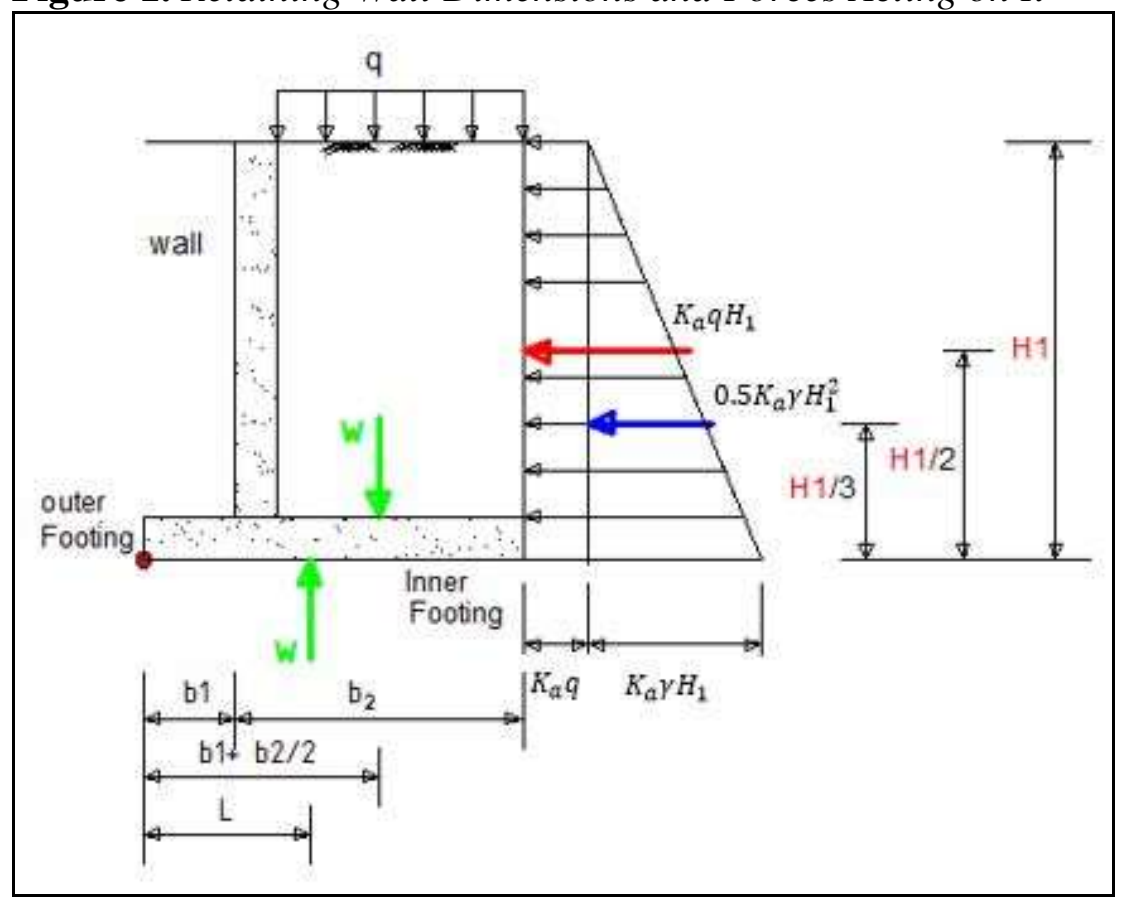

To avoid tension developing at the inner footing (heel slab), the vertical load (W) must be situated within the middle third of the base. This implies, (Bhatt et al., 2013):

$\frac{b_{1}}{b_{2}} \geq 0.25 K_{a}\left(\frac{H_{1}}{b_{2}}\right)^{2}\left[\frac{1+3 \frac{q}{\gamma H_{1}}}{1+\frac{q}{\gamma H_{1}}}\right]-0.25$

The maximum and minimum soil pressure at both ends of the base slab calculated for service load, in case eccentricity lies within the middle third, can be calculated as, see Figure 2:

$p_{\max , \min }=\frac{\Sigma W}{A} \pm \frac{\Sigma M}{W_{e l}}$

The maximum soil pressure $\left(\mathrm{p}_{\max }\right)$ must not exceed the allowable bearing capacity $\left(\mathrm{q}_{\mathrm{a}}\right)$ of the soil, i.e.

$P_{\max } \leq q_{a}$ 
Figure 2. Resultant Loading on the Heel and Toe Projection

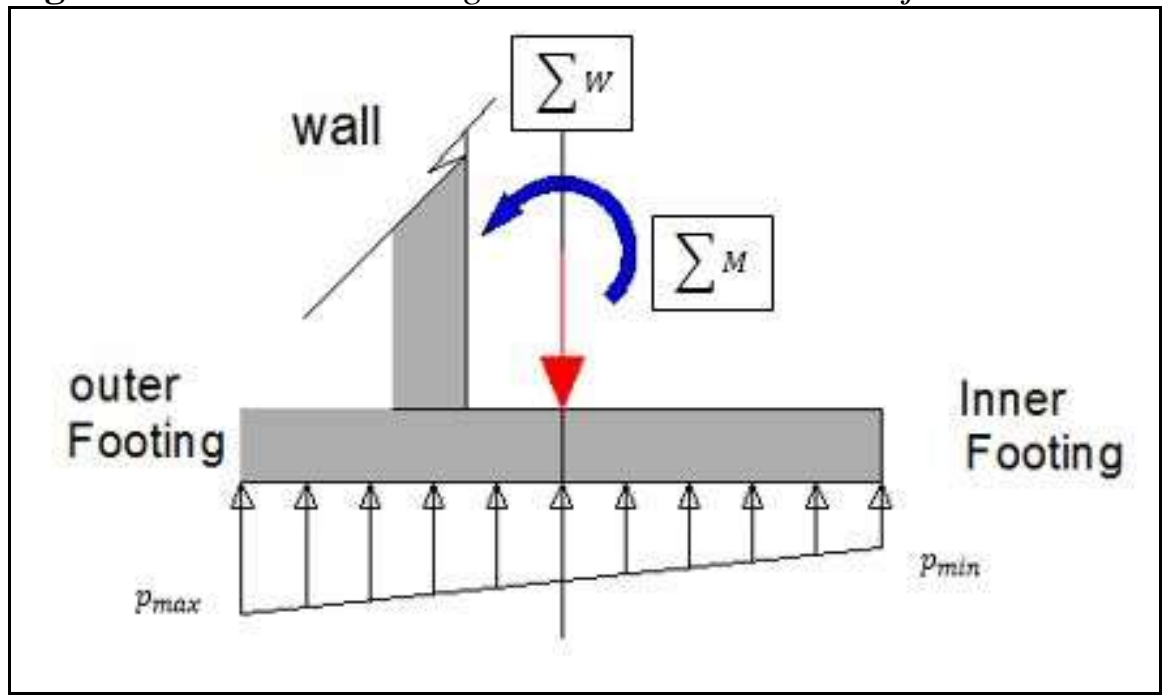

\section{Strength Checking}

The ultimate applied design bending moment $\left(\mathrm{M}_{\mathrm{Ed}}\right)$ acting at the bottom of the stem wall, with a partial load factor $(\gamma \mathrm{f}=1.5)$ as per EC2, (Eurocode 2, 2004) can be expressed as:

$M_{E d}=\left(0.5 K_{a} \gamma H^{3} / 3+K_{a} q H^{2} / 2\right) \gamma_{f}$

For a given amount of steel reinforcement in the wall $\left(\mathrm{A}_{\mathrm{sw}}\right)$, the resisting design moment of the wall $\left(\mathrm{M}_{\mathrm{Rd}}\right)$ will be:

$M_{R d}=0.87 f_{y k} A_{s w} Z$

Where

$z=d\{0.5+\sqrt{(0.25-K / 1.134)}\}$

$K=M_{E d} /\left(b d^{2} f_{c k}\right) \leq 0.192$

The area of steel should be greater than the minimum required area of tension steel $\left(\mathrm{A}_{\mathrm{s}, \mathrm{min}}\right)$ to control any cracking as specified by EC2, (Eurocode 2, 2004):

$A_{s, \min }=0.26\left(f_{c t m} / f_{y k}\right) b d \geq 0.0013 b d$

The term (b) in Eq. (16) and (17) is the width of the cross section. As the design considers unit length of the retaining wall, then (b) is taken as $1000 \mathrm{~mm}$. 
In order to satisfy bending strength requirement of the stem wall, the resisting moment of the wall should be equal or greater than the applied design moment, i.e.

$M_{R d} \geq M_{E d}$

Calculating the horizontal pressure at the top and at distance $\mathrm{d}$ from the fixed base $(\mathrm{H}-\mathrm{d})$ of the wall, the average pressure can be found as:

$P_{a v}=\left(p_{0}+p_{H-d}\right) / 2$

The ultimate design shear force at distance $d$ from the bottom of the stem wall will be:

$V_{E d}=p_{a v}(H-d) \gamma_{f}$

The resistingshear force of the wall as per EC2, (Eurocode 2, 2004) is:

$V_{R d, c}=0.12 k\left(100 \rho_{1} f_{c k}\right)^{0.33} b_{w} d \geq\left(0.035 k^{1.5} f_{c k}^{0.5}\right) b_{w} d$

Where

$\rho_{1}=A_{s w} /\left(b_{w} d\right)$

$k=1+\sqrt{(200 / d)} \leq 2.0$

The term $\left(b_{w}\right)$ in Eq. (21) and (22) is the smallest width of the cross section. As the design considers unit length of the retaining wall, then $\left(b_{w}\right)$ is taken as $1000 \mathrm{~mm}$.

In order to satisfy shear strength requirement of the stem wall, the resisting shear force of the wall should be equal or greater than the applied design moment, i.e.

$V_{R d, c} \geq V_{E d}$

The procedure for checking the bending and shear for the base slab is similar to that of the stem wall as presented through equations $13-24$, but using relevant dimensions of the slab. For more details for the full procedure for the design and check of the wall base slab, one can refer to the work of Ahmed (2015). 
Vol. 5, No. 3 Mohammad et al.: Optimum Design of Reinforced Concrete Cantilever...

\section{Optimization Formulation} 2009):

Structural optimization problem can mathematically be expressed as, (Rao,

Find the set of (n) design variables,

$\{\mathrm{x}\}=\left\{\mathrm{x}_{1}, \mathrm{x}_{2}, \mathrm{x}_{3}, \ldots . . \mathrm{x}_{\mathrm{n}}\right\}$

which minimizes the objective function defined by:

$$
Z=f(\{x\})=f\left(x_{1}, x_{2}, x_{3}, \ldots \ldots, x_{n}\right)
$$

subjected to (m) behavioural (implicit) constraints,

$$
g_{j}(\{x\})=g_{j}\left(x_{1}, x_{2}, x_{3}, \ldots \ldots, x_{n}\right) \leq 0
$$

and (n) side (explicit) constraints,

$$
\{\mathrm{L}\} \leq\{\mathrm{x}\} \leq\{\mathrm{U}\}
$$

\section{Design Parameters}

The independent design parameters are:

$\mathrm{d}^{\prime} \quad$ Concrete cover measured to the centre of the reinforcement; $50 \mathrm{~mm}$

q Surcharge load; $1 \mathrm{kN} / \mathrm{m}^{2}-17 \mathrm{kN} / \mathrm{m}^{2}$

$q_{a} \quad$ Allowable bearing capacity of the soils; $100 \mathrm{kN} / \mathrm{m}^{2}$

$\mu \quad$ Coefficient of friction between the base slab and the soil; $0.45-0.7$

$\gamma \quad$ Unit weight of soil; $16 \mathrm{kN} / \mathrm{m}^{3}-21 \mathrm{kN} / \mathrm{m}^{3}$

$\varphi \quad$ Angle of internal friction; $30^{\circ}$

$\mathrm{f}_{\mathrm{ck}} \quad$ Characteristic cylinder compressive strength of concrete; $30 \mathrm{MPa}$

$\mathrm{f}_{\mathrm{yk}} \quad$ Characteristic yield strength of reinforcing steel; $500 \mathrm{MPa}$

$C_{s} / C_{c}$ Steel to concrete cost ratio; 5,10 or 20

$C_{f} / C_{c} \quad$ Formwork to concrete cost ratio; 0.2

$C_{e} / C_{c}$ Excavation to concrete cost ratio; 0.2

\section{Design Variables}

The design variables for a RC cantilever retaining wall are, see Figure 3.

$X_{1}=T_{w} \quad$ Thickness of stem wall

$X_{2}=A_{s w} \quad$ Area of steel reinforcement required for stem wall 
$X_{3}=T_{b} \quad$ Thickness of base slab

$X_{4}=A_{s b} \quad$ Area of steel reinforcement required for base slab

$X_{5}=W_{h} \quad$ Width of heel slab

$X_{6}=W_{t} \quad$ Width of toe slab

Figure 3. Design Variables of RC Cantilever Retaining Wall

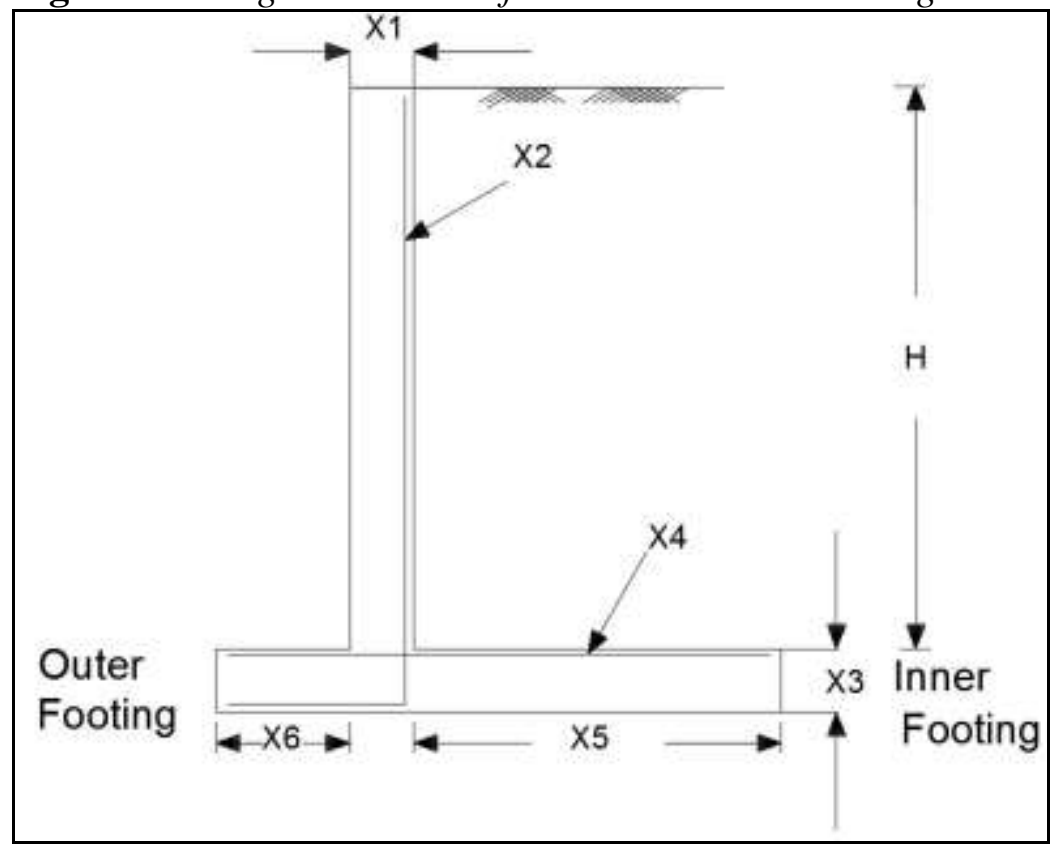

Objective Function

The objective function considered in this study is the minimum cost of the material and excavation per meter length of a cantilever retaining wall. This can be formulated as follows:

$Z=Z_{\text {conc }}+Z_{\text {steel }}+Z_{\text {form }}+Z_{\text {excav }}$

Where

$$
\begin{aligned}
& Z_{\text {conc }}=C_{c}\left[\left(H \times X_{1}\right)+\left(X_{1}+X_{5}+X_{6}\right) X_{3}\right] \\
& Z_{\text {steel }}=C_{s}\left(X_{2}+X_{4}\right) \gamma_{s} \\
& Z_{\text {form }}=2 C_{f}\left(H+X_{3}\right) \\
& Z_{\text {excav }}=C_{e}\left[\left(H+X_{3}\right)\left(X_{1}+X_{5}+X_{6}\right)\right]
\end{aligned}
$$


Vol. 5, No. 3 Mohammad et al.: Optimum Design of Reinforced Concrete Cantilever...

By dividing Eq. (28) by the unit cost of concrete $\left(\mathrm{C}_{\mathrm{c}}\right)$, the total cost of the wall can be expressed in term of cost ratios, and in this case it will be applicable to any currency unit. Thus:

$\frac{Z}{C_{c}}=\frac{Z_{\text {conc }}}{c_{c}}+\frac{Z_{\text {steel }}}{C_{c}}+\frac{Z_{\text {form }}}{C_{c}}+\frac{Z_{\text {excav }}}{C_{c}}$

\section{Constraints}

To obtain the optimum design for a cantilever retaining wall, it is required that the following constrained functions should be satisfied:

$$
\begin{array}{ll}
\mathrm{g}_{1}: & \mathrm{X}_{1} \leq 1000 \\
\mathrm{~g}_{2}: & \mathrm{X}_{1} \geq 100 \\
\mathrm{~g}_{3}: & \mathrm{X}_{2} \leq 10000 \\
\mathrm{~g}_{4}: & \mathrm{X}_{2} \geq 100 \\
\mathrm{~g}_{5}: & \mathrm{X}_{3} \leq 1000 \\
\mathrm{~g}_{6}: & \mathrm{X}_{3} \geq 100 \\
\mathrm{~g}_{7}: & \mathrm{X}_{4} \leq 10000 \\
\mathrm{~g}_{8}: & \mathrm{X}_{4} \geq 100 \\
\mathrm{~g}_{9}: & \mathrm{X}_{5} \leq 4000 \\
\mathrm{~g}_{10}: & \mathrm{X}_{5} \geq 500 \\
\mathrm{~g}_{11}: & \mathrm{X}_{6} \leq 2000 \\
\mathrm{~g}_{12}: & \mathrm{X}_{6} \geq 100 \\
\mathrm{~g}_{15}: & p_{\max } \leq 100 \\
\mathrm{~g}_{13}: & \frac{X_{6}}{X_{5}+X_{1}}-0.25 K_{a}\left(\frac{H_{1}}{X_{5}+X_{1}}\right)^{2}\left[\frac{1+3 \frac{q}{\gamma H_{1}}}{1+\frac{q}{\gamma H_{1}}}\right]+0.25 \geq 0 \\
& \\
\mathrm{~g}_{14} & \\
&
\end{array}
$$


$\mathrm{g}_{16}: \quad F S_{\text {ovtr }} \geq 1$

$\mathrm{g}_{17}: \quad K \geq 0.196$

$\mathrm{g}_{18}: \quad X_{2}-A_{s, \min } \geq 0$

$\mathrm{g}_{19}: \quad M_{R d}-M_{E d} \geq 0$

$\mathrm{g}_{20}: \quad V_{R d, c}-V_{E d} \geq 0$

Constraints $g_{1}$ to $g_{12}$ are the lower and upper feasible limits for the design variables, as presented in Figure 4. Constraints $g_{13}$ to $g_{20}$ define the stability and strength requirements according EC2 as have been previously explained above in the "Design Formulation" section.

Figure 4. Lower and Upper Feasible Limits for the Design Variables

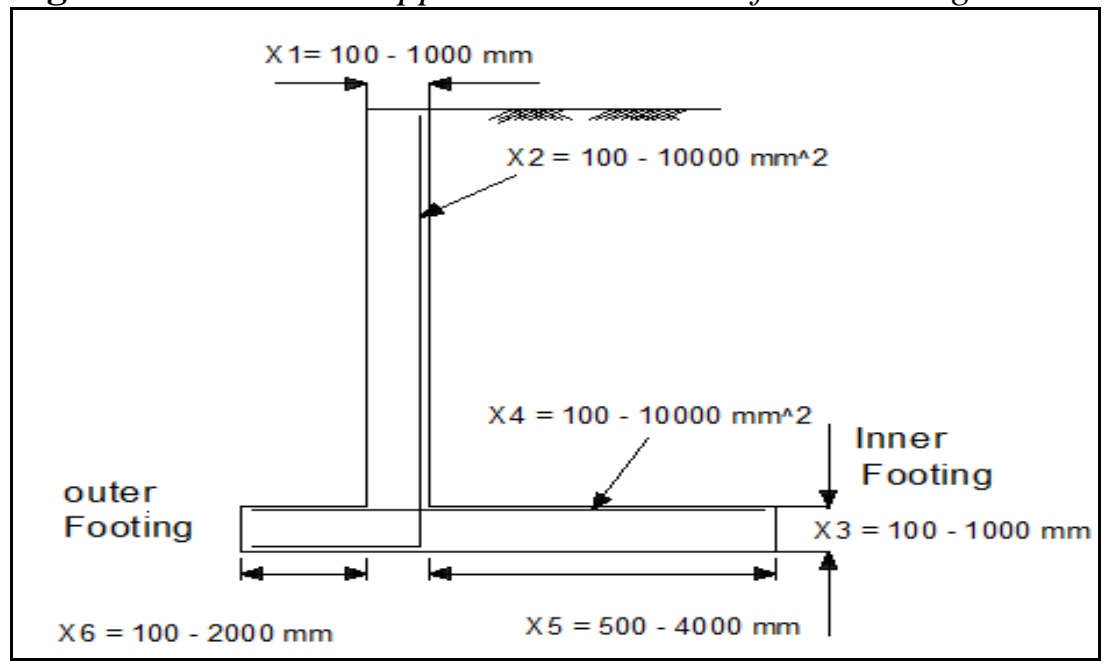

\section{Optimization Tool and Technique}

For the optimization process, the evolutionary method which is a combination of genetic algorithm and local search techniques was adopted in this work for valid reasons. Evolutionary method can effectively solve highly nonlinear problems and problems that feature discontinuous functions as demonstrated by several works available in the literature. The popularity of the evolutionary method may also be attributed to its availability as one of the solving methods in Solver add-in tool of Microsoft Excel. This implies that it is freely available and no need to pay for extra license to run any optimization problem. Moreover, Microsoft Excel provides users with an easy to use grid interface that can organize and manage vast amounts of data. There is no special training required to use the system and is the world's leading spreadsheet software. For the purpose 
of implementing the evolutionary method, Solver add-in of Microsoft Excel was utilized as an optimization tool.The main steps required for using Excel Solver are as follows:

- Creating an Excel worksheet to model the problem. In this spreadsheet a full set of design calculations were produced that allows for variations in the values. It is necessary to identify and highlight the cells allocated for the design parameters, design variable, objective function and the constraints for ease of referencing and tracking.

- Invoking the Solver which resulted in the display of the Solver Parameters dialog box as shown in Figure 5. In this area, optimization of the design model will actually take place after specifying the cells that contain the objective function, design variables and the constraints.

- Selecting a Solving Method which gives the designer the option of choosing the appropriate method of optimization. In this instance the Evolutionary method was employed.

- Clicking Solve button which causes the result dialogue box a popping up after a few seconds, see Figure 5. Selecting OK button would close the Solver parameters dialogue box and the optimum solution was revealed. Depending on the nature and size of the problem, the Solver might give a notification of an error message which means an appropriate solution satisfying all the constraints could not be found. This is merely a request for the use to make practical changes of the initial starting values of the design variables and repeat the process until a feasible solution is determined.

Figure 5. Solver Parameter Dialogue Window

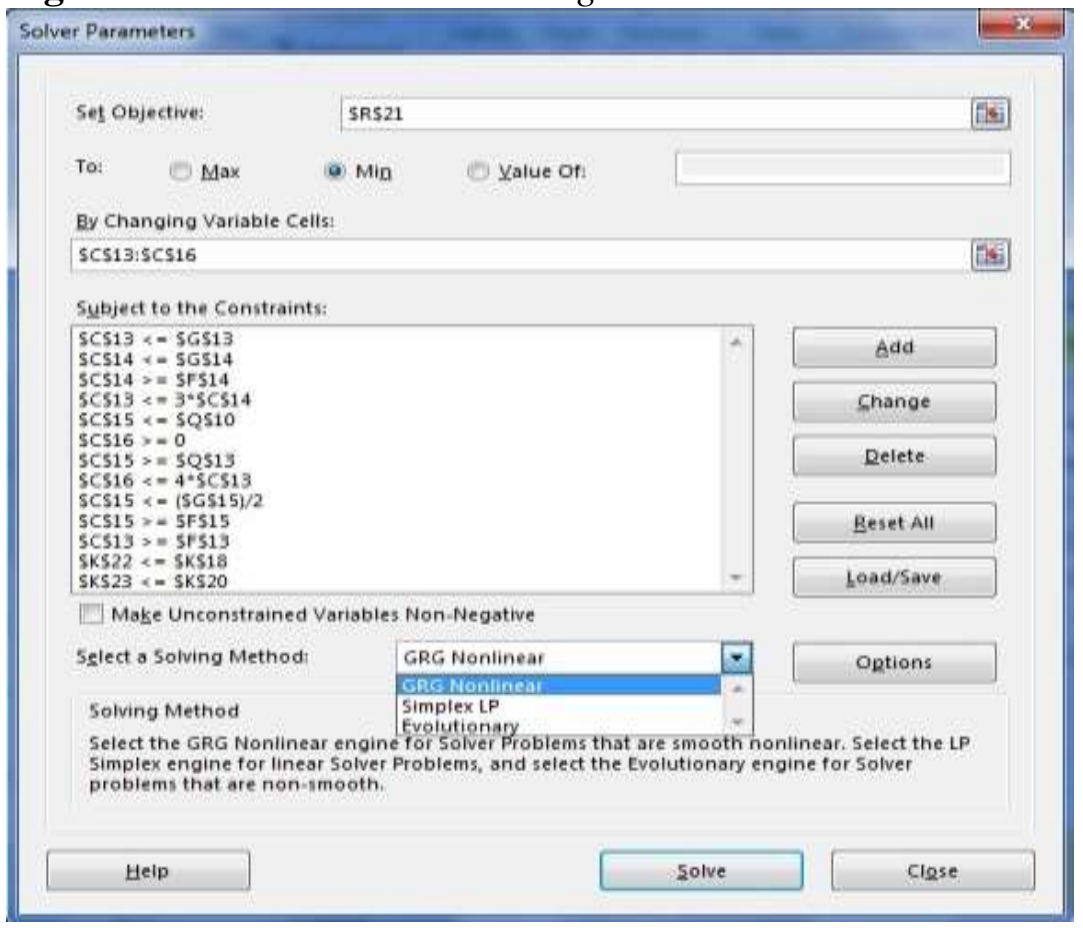




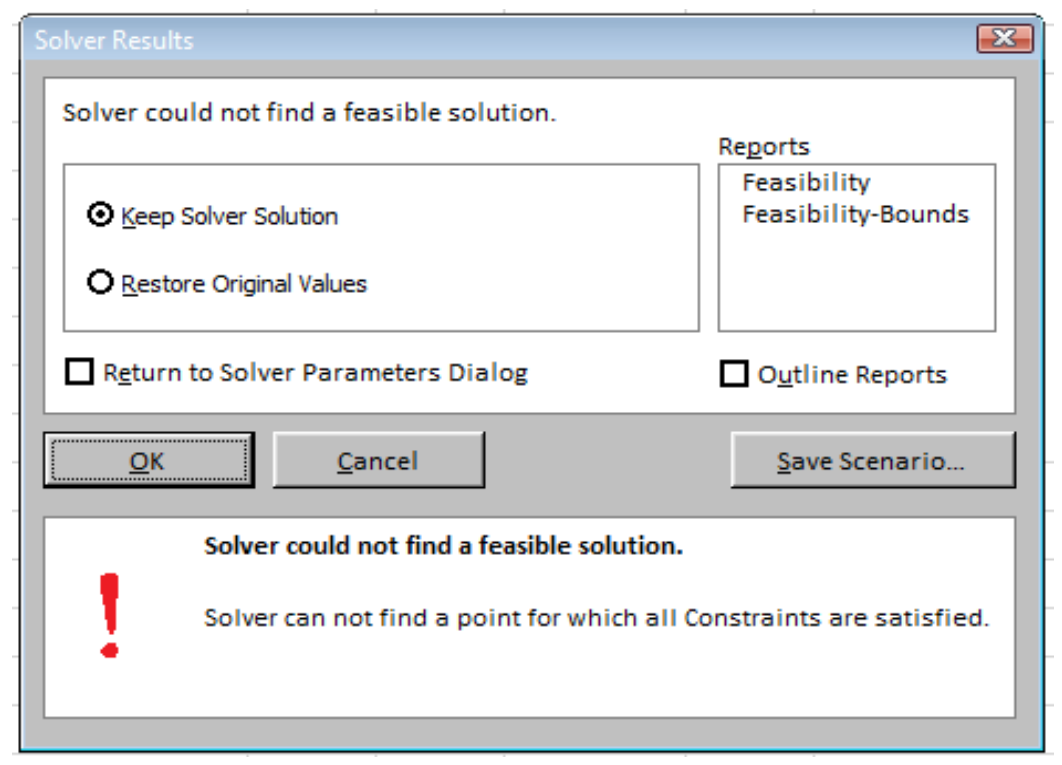

\section{Results and Discussion}

Several practical cases were solved and presented here in order to find out the effect of main design parameters such as wall height, surcharge load, angle of friction, steel to concrete cost ratio and unit weight of the soil on the optimum cost of the retaining wall and the optimum values of the retaining wall dimensions, namely, thickness of stem wall, thickness of base slab, widths of heel and toe.

Referring to Figure 6, a range of wall height between $2.5 \mathrm{~m}-7.5 \mathrm{~m}$ was investigated. The sensitivity of the variation of steel to concrete cost ratio $\left(C_{s} / C_{c}\right)$ between 5 and 20 were also considered. The unit weight of the soil $(\gamma)$ was taken as $18 \mathrm{kN} / \mathrm{m}^{3}$ and coefficient of friction $(\mu)$ was 0.5 and the surcharge load $=15 \mathrm{kN} / \mathrm{m}^{2}$. It is worthwhile to mention that the formwork to concrete cost ratio $\left(C_{f} / C_{c}\right)$ and excavation to concrete cost ratio $\left(C_{e} / C_{c}\right)$ was kept at constant value of 0.2 for all cases considered in this work. It can be observed that there is a direct relation between the optimum cost and wall height. As the wall is increased three times (from $2.5 \mathrm{~m}$ to $7.5 \mathrm{~m}$ ) the cost is almost increased 5 times. This observation sounds quite logic because the taller the retaining wall, the higher the active soil pressure exerting on the structure, hence, higher sliding force and overturning moment as well as higher bending moments at the critical sections of the stem wall and base slab. Hence, relatively bigger cross sections of the stem wall and base slab and more reinforcing steel might be required to satisfy stability and strength requirements. This will definitely result in higher overall cost of the structure. On the other hand, very little change of no more than $5 \%$ of the optimum cost was noticed as the steel to concrete ratio was increased from 5 to 20. Thus, one can conclude that the optimum cost of the retaining wall is slightly sensitive to the variation of the steel to concrete cost ratio. 
Figure 7 shows the influence of the coefficient of friction on the optimum cost of the structure. In this case, the following design parameters are fixed: unit weight of the soil $=18 \mathrm{kN} / \mathrm{m}^{3}$, wall height $=3.5 \mathrm{~m}$, surcharge load $=$ $15 \mathrm{kN} / \mathrm{m}^{2}$. Three values of steel to concrete ratio of 5,10 and 20 were again taken into account. It can be noticed that change the coefficient of friction from 0.45 to 0.7 does not affect the optimum cost of the retaining wall. This implies that the constraint related to the sliding stability $\left(\mathrm{g}_{15}\right)$ is slack (i.e. inactive), hence, does not control the optimum design of the retaining wall. In addition, when the cost ratio is increased from 5 to 20 for any given coefficient of friction, the optimum cost is increased from 4.96 to 5.21, i.e. the increase is no more than 5\%. Once again it can be concluded that the optimum cost of the retaining wall is not that sensitive to the change of steel to concrete cost ratio.

Figure 8 displays the relationship between the optimum cost of the retaining wall and applied surcharge load for defined values of unit weight of the soil $=18 \mathrm{kN} / \mathrm{m}^{3}$, wall height $=3.5 \mathrm{~m}$, coefficient of friction $=0.5$ and steel to concrete ratio $=5,10$ and 20. It can be seen that there is almost a linear direct relation with relatively gentle slope between the optimum cost and surcharge load. Increasing the surcharge from $1 \mathrm{kN} / \mathrm{m}^{2}$ to $17 \mathrm{KN} / \mathrm{m}^{2}$ will lead to increase the optimum cost by about $14 \%$ (i.e. from 4.34 to 5.02 for steel to concrete cost ratio $=5$; and from 4.52 to 5.30 for cost ratio $=20$ ). The reason for such relationship is that increasing the surcharge load will increase the lateral active earth pressure by a factor of $K_{a}$ which is 0.33 for an angle of internal friction $\varphi=30^{\circ}$ considered in these examples. Hence, the sliding force, overturning moment and internal forces (shear force and bending moment at critical sections) will be increased by same factor accordingly. This means relatively larger dimensions of the retaining wall elements are required to resist these force, and this will systematically lead to higher cost of the structure. The optimum cost of the retaining wall, again, shows little change by no more than $5 \%$ with the variation of the steel to concrete cost ratio from 5 to 20 .

Figure 9 demonstrates that the optimum cost of the retaining wall is inversely proportional to the unit weight of the soil with almost linear relationship at gentle slope. As the unit weight of the soil is increased from $16 \mathrm{kN} / \mathrm{m}^{3}$ to $21 \mathrm{kN} / \mathrm{m}^{3}$, the optimum cost of the retaining wall reduced about $2 \%$ (i.e. from 5 to 4.91 for steel to concrete cost ratio $=5$; and from 5.26 to 5.19 for cost ratio $=20$ ). This might be attributed to the fact that the denser the soil is the higher the stabilizing forces acting on the structure in terms of vertical force and bending moment that counteract the effect of destabilizing forces in terms of sliding force and overturning moment. Hence, relatively smaller dimensions of the stem wall and base slab and reinforcing steel are sufficient to satisfy stability and strength requirements. This means lesser overall cost of the structure is achieved. One further observation worth noting is that, the variation of optimum cost of the retaining wall is round $5 \%$ as the steel to concrete ratio change from 5 to 20 for any given unit weight of soil.

Table 1 presents the optimum values for the design variables of retaining wall dimensions for two cases of stem wall height of $3.5 \mathrm{~m}$ and $7.5 \mathrm{~m}$.For both cases, the following design parameters are assumed: unit weight of the soil = 
$18 \mathrm{kN} / \mathrm{m}^{3}$, surcharge load $=15 \mathrm{kN} / \mathrm{m}^{2}$, base coefficient of friction $=0.5$, steel to concrete ratio $=10$. It is worthwhile to mention that these results are rounded to nearest practical figures. One can note that the optimum stem thickness to retaining wall height ratio $\left(\mathrm{T}_{\mathrm{w}} / \mathrm{H}_{1}\right)$ is 0.07 and 0.06 for stem height $3.5 \mathrm{~m}$ and $7.5 \mathrm{~m}$ respectively. Similar values are obtained for the optimum base slab thickness to retaining wall height ratio $\left(\mathrm{T}_{\mathrm{b}} / \mathrm{H}_{1}\right)$. In addition, the optimum base slab width to retaining wall height ratio $\left(\mathrm{B} / \mathrm{H}_{1}\right)$ is 0.72 and 0.64 for stem height between $3.5 \mathrm{~m}$ and $7.5 \mathrm{~m}$ respectively. By comparing these results with those published in the literature, it reveals good agreement with some degree of discrepancies. For example, Bowles (2001) recommended a ratio between 0.08 to 0.1 for $\left(\mathrm{T}_{\mathrm{w}} / \mathrm{H}_{1}\right), 0.1$ for $\left(\mathrm{T}_{\mathrm{b}} / \mathrm{H}_{1}\right)$ and between 0.4 to 0.7 for $\left(\mathrm{B} / \mathrm{H}_{1}\right)$. On the other hand Das (2010) suggested a ratio of 0.1 for $\left(\mathrm{T}_{\mathrm{w}} / \mathrm{H}_{1}\right)$ and $\left(\mathrm{T}_{\mathrm{b}} / \mathrm{H}_{1}\right)$, and between 0.5 to 0.7 for $\left(\mathrm{B} / \mathrm{H}_{1}\right)$. The main reason for the difference in results is that the present work followed optimisation technique to solve the problem, whereas those given by others as referenced were merely tentative approximate values based on practical experience.

Figure 6. Minimum Cost versus Height of the Wall

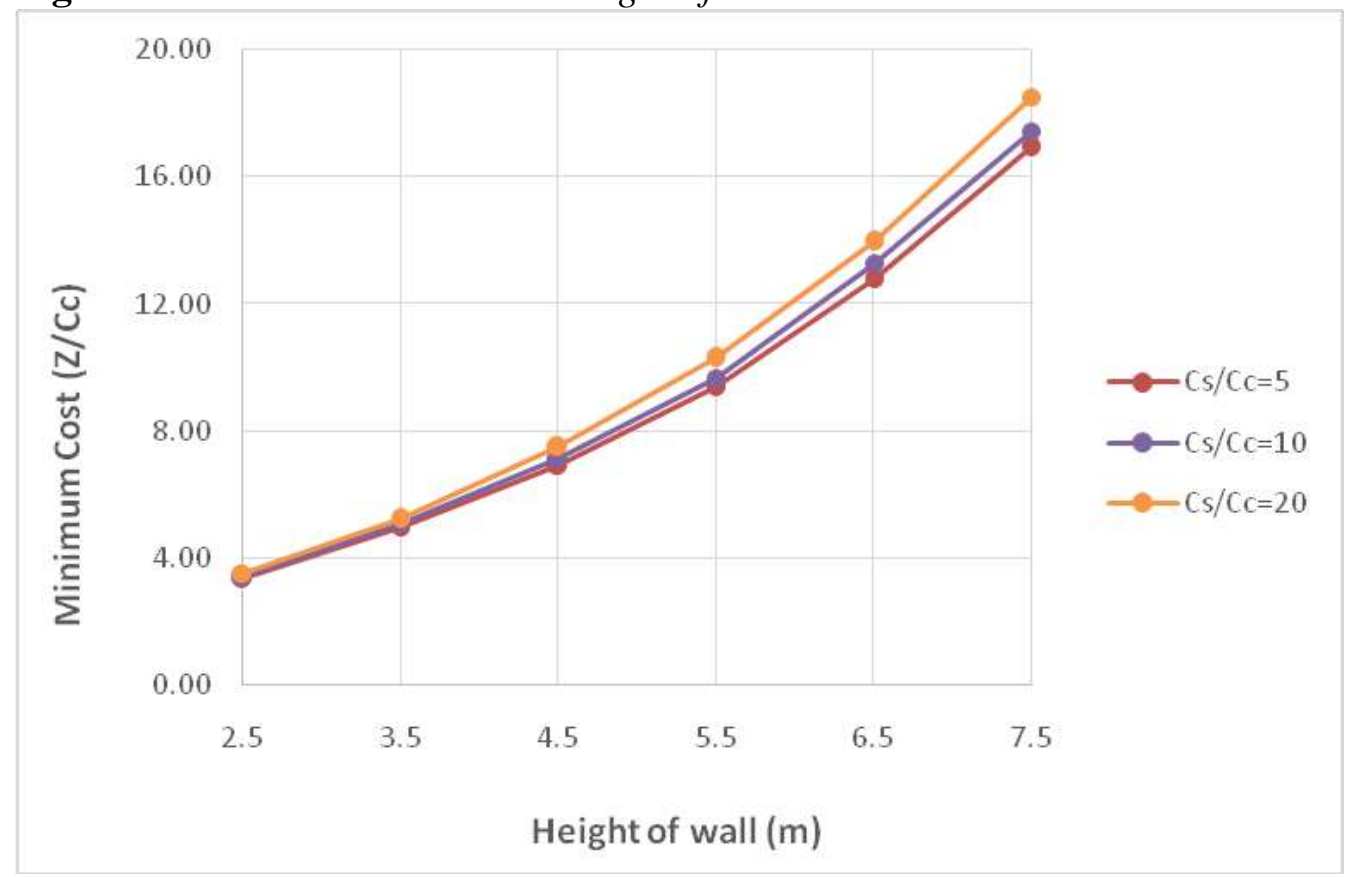


Vol. 5, No. 3 Mohammad et al.: Optimum Design of Reinforced Concrete Cantilever...

Figure 7. Minimum Cost versus Coefficient of Friction

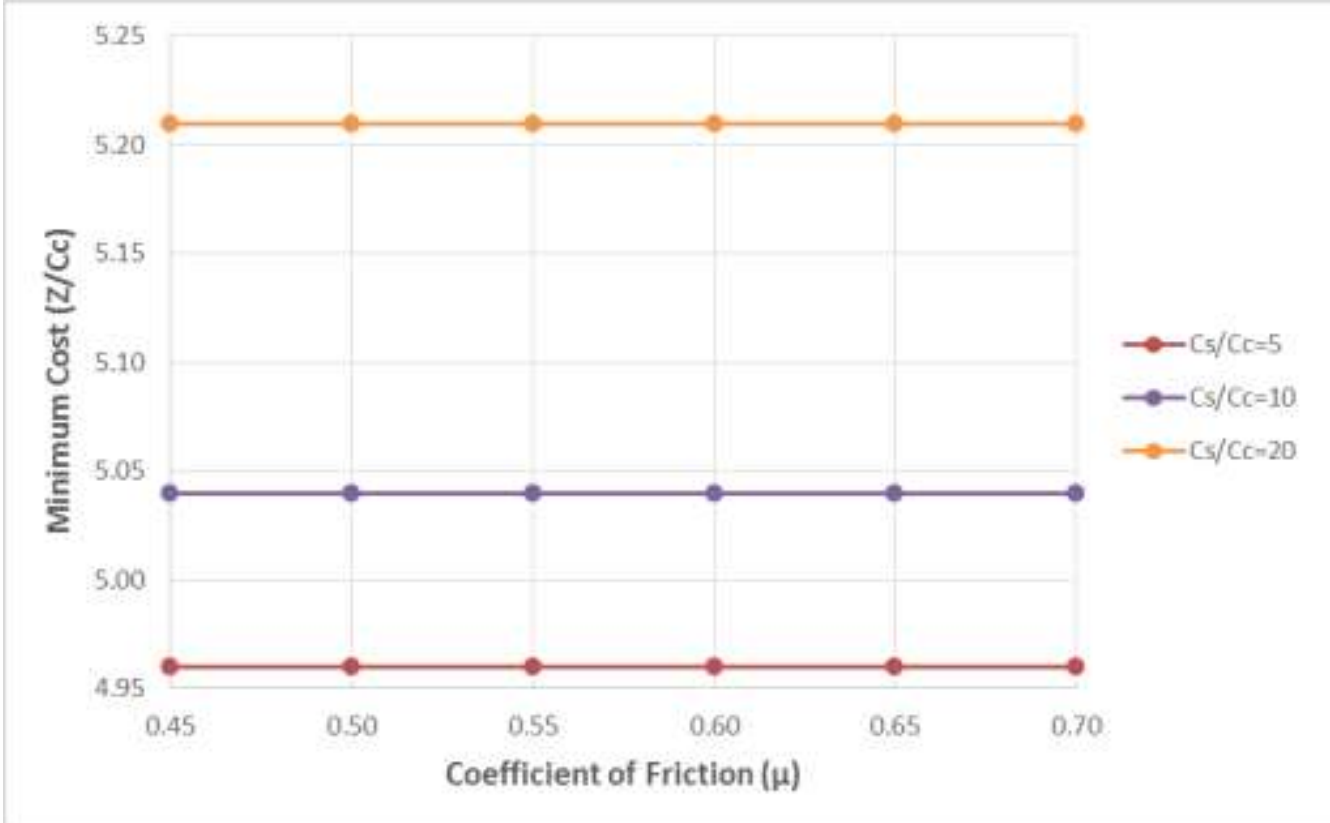

Figure 8. Minimum Cost versus Surcharge Load

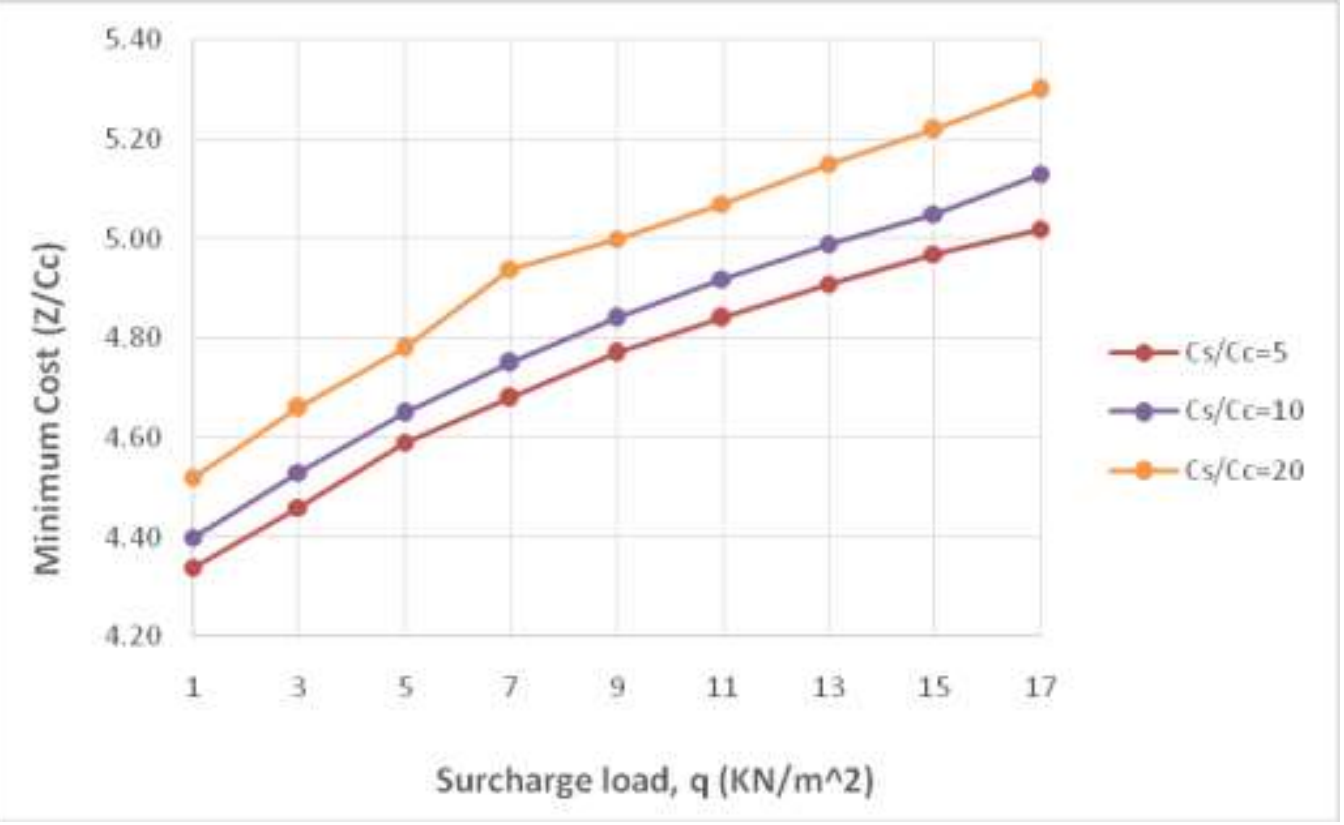


Figure 9. Minimum Cost versus Unit Weight of Soil

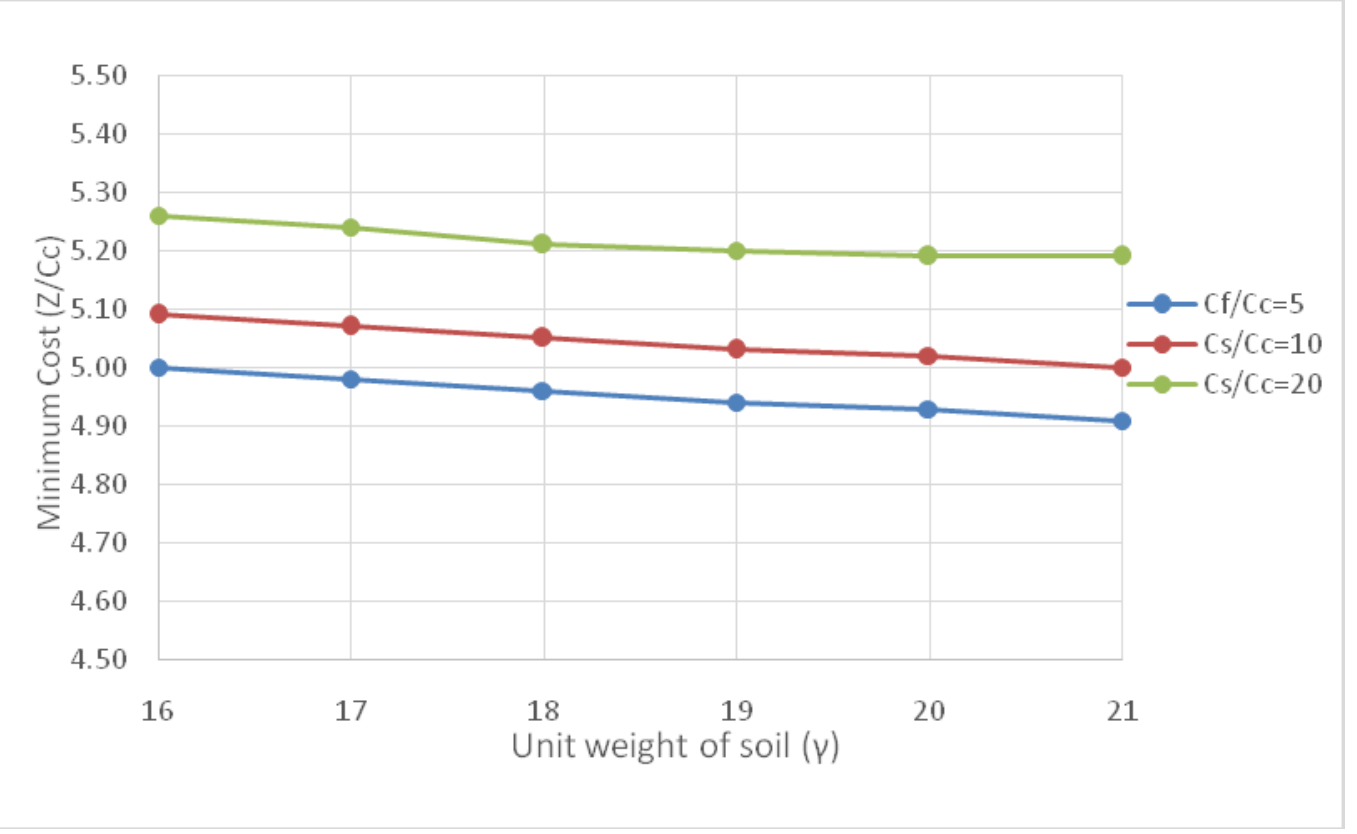

Table 1. Optimum Values of the Retaining Wall Dimensions

\begin{tabular}{|l|c|c|}
\hline \multirow{2}{*}{ Retaining wall dimensions } & \multicolumn{2}{c|}{ Height of stem wall $(\mathrm{H})$} \\
\cline { 2 - 3 } & 3.5 & 7.5 \\
\hline Thickness of stem wall $\left(\mathrm{T}_{\mathrm{w}}\right)$ & 0.25 & 0.47 \\
\hline Thickness of base slab $\left(\mathrm{T}_{\mathrm{b}}\right)$ & 0.25 & 0.45 \\
\hline Width of heel slab $\left(\mathrm{W}_{\mathrm{h}}\right)$ & 1.63 & 2.72 \\
\hline Width of toe slab $\left(\mathrm{W}_{\mathrm{t}}\right)$ & 0.63 & 1.60 \\
\hline Height of retaining wall $\left(\mathrm{H}_{1}\right)$ & 3.75 & 7.97 \\
\hline Width of base slab $(\mathrm{B})$ & 2.51 & 4.79 \\
\hline Stem thickness / Retaining wall height $\left(\mathrm{T}_{\mathrm{w}} / \mathrm{H}_{1}\right)$ & 0.07 & 0.06 \\
\hline Base slab thickness / Retaining wall height $\left(\mathrm{T}_{\mathrm{b}} / \mathrm{H}_{1}\right)$ & 0.07 & 0.06 \\
\hline Base slab width / Retaining wall height $\left(\mathrm{B} / \mathrm{H}_{1}\right)$ & 0.72 & 0.64 \\
\hline
\end{tabular}

All dimensions are in meters.

\section{Conclusions}

This investigation presents an extensive study to design a cantilever retaining wall with minimum cost, using Evolutionary method embedded within Excel's Solver add-in tool of Microsoft Excel. The following conclusions can be highlighted:

- The optimum design of reinforced concrete cantilever retaining wall can be regarded as rather complicated when compared with other conventional concrete structures. This is due to rigorous checking requirement for overall external stability and internal strength at critical sections. External stability includes overturning, sliding, bearing capacity and eccentricity 
check. Whereas, internal stability is required in order to make sure that the shear and bending resistance of each part of the retaining wall, namely, stem, heel and toe slab are at least equal or greater than the applied design forces.

- Therefore, powerful optimization technique is necessary to tackle such problem. Hence, Evolutionary method which is a combination of genetic algorithm and local search techniques was adopted in this work. This is because of its efficiency in dealing with highly nonlinear problems and cases that feature non-smooth functions. Equally important, the evolutionary method is freely available within the Solver add-in tool of Microsoft Excel, thus, no need to pay for extra license for running any optimization problem.

- Throughout solving wide range of practical design scenarios, it was demonstrated that the optimum cost of the retaining wall is directly proportional to the wall height with relatively steeper slope; as well as with the surcharge load, but with relatively gentler slope. On the other hand, the optimum cost of the retaining wall is found to be inversely proportional to the unit weight of the soil with almost linear relationship at gentle slope.

- Changing the value of coefficient of friction within a specific range sounds to have negligible effect on the minimum cost of the structure.

- Finally, comparing the optimum values obtained in this study with those published in the literature for the design variables of retaining wall, the accuracy of proposed method and corresponding results is validated.

\section{List of Notations}

$\begin{array}{ll}A_{s, m i n} & \text { Minimum area of steel reinforcement } \\ A_{s b} & \left.\text { Area of steel required for the base slab (design variable } \mathrm{X}_{4}\right) \\ \mathrm{A}_{\mathrm{sw}} & \left.\text { Area of steel required for the stem wall (design variable } \mathrm{X}_{2}\right) \\ \mathrm{B} & \text { Width of the base slab } \\ \mathrm{b} & \text { Width of the cross section, which is unit length of the wall } \\ & (1000 \mathrm{~mm}) \\ \mathrm{b}_{\mathrm{w}} & \text { Smallest width of the cross section, }(1000 \mathrm{~mm}) \\ \mathrm{C}_{c} & \text { Cost of concrete per } \mathrm{m}^{3} \\ \mathrm{C}_{\mathrm{e}} & \text { Cost of excavation per } \mathrm{m}^{3} \\ \mathrm{C}_{\mathrm{f}} & \text { Cost of formwork per } \mathrm{m}^{2} \\ \mathrm{C}_{\mathrm{s}} & \text { Cost of steel per ton } \\ \mathrm{d} & \text { Effective depth of the cross section } \\ \mathrm{d}^{\prime} & \text { Concrete cover measured to the centre of the reinforcement steel } \\ & \text { (mm) } \\ \mathrm{F}_{\text {res }} & \text { Resisting force to sliding } \\ \mathrm{FS}_{\text {ovtr }} & \text { Factor of safety against overturning } \\ \mathrm{FS}_{\text {slid }} & \text { Factor of safety against sliding }\end{array}$


$\mathrm{f}_{\mathrm{ck}} \quad$ Characteristic cylinder compressive strength of concrete (EC2)

$\mathrm{f}_{\mathrm{ctm}} \quad$ Mean tensile strength of concrete

$\mathrm{f}_{\mathrm{yk}} \quad$ Characteristic yield strength of steel (EC2)

$\mathrm{g}_{\mathrm{i}} \quad$ Constraint

$\mathrm{H} \quad$ Height of the stem wall

$\mathrm{H}_{1} \quad$ Total height of the retaining wall including the thickness of base slab

$\mathrm{K}_{\mathrm{a}} \quad$ Active earth pressure coefficient

$\mathrm{M}_{\text {ot }} \quad$ Overturning moment

$\mathrm{M}_{\text {st }} \quad$ Stabilizing (restoring) moment

$\mathrm{M}_{\mathrm{Ed}} \quad$ Applied ultimate design bending moment at the wall base

$\mathrm{M}_{\mathrm{Rd}} \quad$ Resisting design bending moment of the wall

$p_{\text {av }} \quad$ Average pressure acting on the wall

$\mathrm{P}_{\max } \quad$ Maximum soil pressure underneath the base slab

$\mathrm{p}_{\max , \min } \quad$ Maximum or minimum soil pressure underneath the base slab

$\mathrm{P}_{1}$

$q_{a}$

Horizontal force due to lateral earth pressure

$\mathrm{T}_{\mathrm{b}}$

$\mathrm{T}_{\mathrm{W}}$

$\mathrm{V}_{\mathrm{Ed}}$

$\mathrm{V}_{\mathrm{Rd}, \mathrm{c}}$

Allowable bearing capacity

Thickness of the base slab (design variable $\mathrm{X}_{3}$ )

Thickness of stem wall (design variable $\mathrm{X}_{1}$ )

Applied ultimate design shear force

$\mathrm{W}$

$\mathrm{W}_{\mathrm{el}}$

$\mathrm{W}_{\mathrm{h}}$

$\mathrm{W}_{\mathrm{t}}$

$\mathrm{x}_{\mathrm{i}}$

Z

Ultimate resisting shear force of the member

Total vertical load

Elastic section modulus of 1 metre length of the base slab

Width of the heel slab (design variable $\mathrm{X}_{5}$ )

Width of toe slab (design variable $\mathrm{X}_{6}$ )

Design variable

$Z_{\text {conc }}$

Total cost of retaining wall per metre length of the wall

$Z_{\text {excav }}$

$Z_{\text {form }}$

Cost of concrete material per metre length of the retaining wall

$Z_{\text {steel }}$

Cost of excavation per metre length of the retaining wall

$\gamma$

Cost of formwork per metre length of the retaining wall

Cost of steel per metre length of the retaining wall

$\gamma_{\mathrm{G}, \text { fav }}$

Unit weight of soil

$\gamma_{Q}$

Beneficial partial safety factor

Adverse partial safety factor

$\gamma_{\mathrm{f}}$

Partial load factor (1.5)

$\gamma_{s}$

Unit weight of steel $\left(7.85 \mathrm{ton} / \mathrm{m}^{3}\right)$

$\rho_{1} \quad$ Longitudinal reinforcement ratio

$\mu$

Coefficient of friction between the base slab and the soil

$q \quad$ Surcharge load 
Vol. 5, No. 3 Mohammad et al.: Optimum Design of Reinforced Concrete Cantilever...

$\varphi \quad$ Angle of internal friction

\section{References}

Adeli, H. and Sarma, K. C., 2006.Cost Optimization of Structures: Fuzzy Logic, Genetic Algorithms, and Parallel Computing.John Wiley and Sons.

Ahmed, H., 2015. Optimum Design of Reinforced Retaining Walls according to EC2 Code. MSc thesis, University of Nottingham Trent, U.K.

Arora, J. S., 2012. Introduction to optimum design", $3^{\text {rd }}$ edition, Oxford: Elsevier.

Basudhar, P., Lakshman, B. and Dey, A., 2006. Optimal cost design of cantilever retaining walls. India: IGC, Chennai, 14-16.

Belegundu, A. D., and Chandrupatla, T. R., 2011. Optimization Concepts and Applications in Engineering. Second Edition.Cambridge University Press.

Bhatt, P., MacGinley, T.J., and Choo, B.S., 2013. Reinforced concrete design to Eurocodes: design theory and examples.Fourth Edition, CRC Press Taylor \& Francis Group.

Bowles, J. E. 2001. Foundation Analysis and Design. $5^{\text {th }}$ edition, The McGraw-Hill Companies, Inc.

Das, B. M. 2010. Principles of foundation Analysis and Design. Seventh Edition, Cengage Learning.

Eurocode 2, 2004. Eurocode 2 - Design of concrete structures, Part 1: General Rules and Rules for Buildings. BSI British Standard, BS EN 1992-1.

Medhekar, M., 1990. Optimum Design of Free Standing Cantilever Retaining Walls. Master Thesis. Indian Institute of Technology Kanpur, India.

Pei, Y. and Xia, Y. 2012.Design of reinforced cantilever retaining walls using heuristic optimization algorithms. Procedia Earth and Planetary Science, 5, 32-36.

Poursha, M., Khoshnoudian, F. and Moghadam, A. 2011. Harmony search based algorithms for the optimum cost design of reinforced concrete cantilever retaining walls. International Journal of Civil Engineering, 9,1-8.

Rao, S.S., 2009. Engineering Optimization: Theory and Practice. $4^{\text {th }}$ ed., John Whily and Sons.

Sheikholeslami, R., Khalili, B G. and Zahrai, S. M. 2014. Optimum Cost Design of Reinforced Concrete Retaining Walls Using Hybrid Firefly Algorithm. IACSIT International Journal of Engineering and Technology, Vol. 6, No. 6, 2014. 